\title{
Expectações do espírito: Agostinho e o tempo
}

\author{
Expectations of the spirit: Agostinho and the time
}

\author{
ANDRÉ RENAN BATISTELLA NOARA ${ }^{1}$
}

Resumo: O presente estudo tem como objetivo elaborar uma análise referente ao modo com o qual o filosofo medieval Aurélio Agostinho (354-430), mais conhecido por Santo Agostinho, no livro XI de sua obra intitulada Confissões, conceitua o tempo, mais precisamente sua conclusão sobre o futuro. Nesse livro, Agostinho desenvolve uma investigação aprofundada em torno do tempo. Devido à complexidade do tema (tempo), a metodologia abordada para o presente trabalho se dará da seguinte forma: primeiramente, será feita uma diferenciação entre tempo e eternidade, presentes na obra do pensador. Em um segundo momento, será analisada uma possível divisão trabalhada por Agostinho dentro de sua teoria, sendo esta, tempo da mente (concepção de tempo no interior do sujeito) e o tempo externo ao sujeito. Posteriormente, compreendido alguns pontos cruciais da teoria, analisar-se-á o modo como Agostinho concebe o futuro. Acredita-se que o presente trabalho trará para o leitor uma melhor compreensão em relação à forma com que Agostinho conceitua este enigma chamado tempo, assim como compreender a tamanha dificuldade de se encontrar uma resposta objetiva para este problema filosófico.

Palavras-chave: Tempo. Alma. Futuro.

Abstract: This work aims to elaborate an analysis which refers to the way that a medieval philosopher Aurélio Agostinho (354-430), known as Santo Agostinho, in the book XI of his work titled as Confissões (confessions), concepts the time, more precisely his conclusion about the future. In this book, Agostinho develops a deep investigation about the time. Because of the complexity of the theme (time), the methodology to this work will happen in this way: first of all it will be done a distinction between time and eternity, themes that are included in the thinker work. Second, it will be analyzed a possible division worked by Agostinho inside his own theory, the time of the mind (conception of the time on the inside of the subject) and the time outside the subject. After the understanding of some crucial points of the theory, it will be analyzed the way how Agostinho conceived the future. It is believed that this work will bring to the reader a better understanding in relation to the way that Agostinho conceptualizes this enigma called time, and understand the huge difficulty of finding an objective answer to this philosophical problem.

Keywords: Time. Soul. Future.

\section{Introdução}

O pensar filosófico atravessou milênios, e os problemas com os quais os pensadores mais brilhantes da história da filosofia se relacionavam possuem pertinência ainda hoje. Dentre a diversidade de questões filosóficas com as quais os

'Acadêmico do curso de graduação em Filosofia-Licenciatura, 6o fase, da Universidade Federal Fronteira Sul, Campus Erechim. E-mail: andre_noara@hotmail.com. 
"gigantes" da filosofia desenvolveram seus estudos, uma delas, sem dúvida, de grande importância e complexidade, se dá em torno de conceituar o tempo².

O pensador medieval Aurélio Agostinho (354-430), mais conhecido por Santo Agostinho, dedicou parte de sua vida desenvolvendo uma "resposta" para esta questão. Em um de seus escritos filosóficos, intitulado Confissões, mais precisamente no livro XI, Agostinho desenvolve uma análise em torno da questão tempo. A preocupação de Agostinho ao desenvolver esta análise se dá principalmente para responder uma questão de fundo: que faria Deus antes da criação? A fim de elaborar uma resposta para tal questionamento, Agostinho sente a necessidade de conceituar o tempo.

A partir do conceito agostiniano de tempo, tudo o que possui existência no tempo se encontra no presente. Ou seja, qualquer coisa temporal só é porque está no presente. Não é possível alguma coisa existir no passado ou no futuro. A existência enquanto submissa ao tempo se estabelece unicamente no presente. Contudo, é possível haver a existência de uma concepção de passado e futuro no espírito.

De acordo com seu conceito, o tempo passado afeta o espírito em momento presente, através das lembranças que tiveram existência em um momento presente que já não é, ou seja, que já passou. Já o futuro se dá como expectação contida no espírito, ou, através de vaticínio.

O principal foco do presente estudo é desenvolver uma análise em torno do conceito agostiniano de futuro. Porém, para tanto, em um primeiro momento, serão abordadas as diferenças entre tempo e eternidade apresentadas por Agostinho. Após esta primeira abordagem, analisar-se-á uma possível divisão feita por Agostinho em sua teoria do tempo, para, posteriormente, investigar de modo mais preciso sua concepção de futuro. Acredita-se que deste modo possibilitar-se-á uma melhor compreensão da forma com a qual Agostinho conceitua o futuro.

\section{A eternidade e o tempo}

Nos primeiros capítulos do livro XI das Confissões, Agostinho inicia uma reflexão em torno da criação do céu e da terra. Dentro desta reflexão, ele passa a investigar os "métodos" utilizados por Deus na criação desta magnífica e gigantesca obra chamada universo. O problema central que impõe a Agostinho a necessidade de desenvolver um conceito para explicar o que o tempo é, se dá em resposta ao título do capítulo dez: “Que faria Deus antes da criação?” (Conf., XI, 10).

\footnotetext{
${ }^{2}$ Não só para a filosofia, mas também para os maiores gênios da física, o problema tempo se apresentou com grande relevância. Os físicos Isaac Newton (1643-1727) (em sua obra Os Princípios Matemáticos da Filosofia Natural (1687)) e Albert Einstein (1879-1955) (em sua obra Teoria da Relatividade Geral (1916)) passaram parte de sua vida buscando desenvolver respostas para este enigma chamado "tempo".
} 
Visando à formulação de uma resposta para tal questionamento, Agostinho inicia uma argumentação no capítulo dez e a conclui no capítulo treze. De início, o pensador já afirma que:

[...] estão ainda cheios de velhice espiritual aqueles que nos dizem: "Que fazia Deus antes de criar o céu e a terra? Se estava ocioso e nada realizava", dizem eles, "por que não ficou sempre assim no decurso dos séculos, abstendo-se, como antes, de toda ação? Se existiu em Deus um novo movimento, uma vontade nova para dar o ser a criaturas que nunca antes criara, como pode haver verdadeira eternidade, se n'Ele aparece uma vontade que antes não existia?" (Conf., XI, 10, 12).

É possível perceber, através desta passagem, uma crítica de Agostinho àqueles que assim questionam e fazem tais afirmações. No capítulo seguinte, Agostinho desenvolve o porquê desta crítica, entendendo-se, a partir de então, que os que assim se manifestam ignoram a verdade, pois os mesmos não conseguem se "despir" de sua concepção de temporalidade, e, por consequência, acabam por expressar falsas conclusões. Pretender medir a eternidade influenciado pela concepção de temporalidade contida no espírito é um erro. É impossível medir a eternidade através do tempo, pois a eternidade, perpetuamente imutável, é incomparável com o tempo. Este só é o que é por ser composto de momentos que deixam de ser a todo instante, momentos passageiros que jamais serão todo presente, pois, caso o fosse, já não seria mais tempo e sim eternidade, e isso, sem dúvida, é algo que o tempo não é. A eternidade, contrariamente ao tempo, não constitui-se de momentos passageiros, mas sim do fato de tudo ser presente.

Como afirma Sérgio Danilas, a eternidade "compreende o atemporal, o indescritível, o inefável e de lá que o Verbo sempre presente, profere sua palavra de modo simultâneo e eterno." (DANILAS, 2009, p.04) Ou seja, não há passado nem futuro na eternidade, mas sim um eterno presente. A concepção de passado e futuro que se estabelece no espírito humano, são "atributos" que definem a "identidade" do tempo. Os mesmos existem apenas no espírito dos indivíduos "dotados" de temporalidade. No entanto, apesar de pertencerem ao âmbito temporal, se originam a partir de algo que é eterno. Ou seja, "[...] o passado é impelido pelo futuro e [...] todo o futuro está precedido dum passado, e todo o passado e futuro são criados e dimanam d'Aquele que sempre é presente" (Conf., XI, 11,13).

No final do capítulo 11 é possível perceber o quão difícil é, até mesmo para Agostinho, fundamentar uma explicação para tal afirmação acima citada:

Quem poderá prender o coração do homem, para que pare e veja como a eternidade imóvel determina o futuro e o passado, não sendo ela nem passado nem futuro? Poderá, porventura, a minha mão que escreve explicar isto? Poderá a atividade da minha língua 
conseguir pela palavra realizar empresa tão grandiosa? (Conf., $\mathrm{XI}, 11,13)$.

Na sequência, entre os capítulos 12 e 13, Agostinho apresenta uma resposta para a questão levantada anteriormente ("Que faria Deus antes da criação?”). Como mencionado há pouco, eternidade e tempo são distintos. Na eternidade, não existe momentos passageiros, pelo contrário, nada passa, tudo é presente. A palavra “antes”, remete a um momento que já não é, ou seja, que foi presente e se tornou passado. Deus é eterno. Logo, não faz o menor sentido questionar: "o que faria Deus antes da criação?”. Na eternidade não existe antes nem depois, nada foi nem nada será, tudo é. Não houve tempo antes da criação, assim como não há tempo na eternidade. O tempo passa a existir na criação. Logo, o tempo também é uma criatura. Ou seja, o tempo foi criado por Deus, assim como tudo àquilo que é temporal. Pensar em um tempo anterior à criação do próprio tempo, é uma contradição lógica. "Criastes todos os tempos e existis antes de todos os tempos. Não é concebível um tempo em que possa dizer-se que não havia tempo" (Conf., XI, $13,16)$.

Após estabelecer esta diferenciação entre o conceito de tempo e eternidade, Agostinho, a partir do capítulo 14, inicia uma análise mais aprofundada em relação à definição do tempo. É o que será visto a seguir.

\section{Sobre o tempo}

Avançando em sua investigação, Agostinho "se depara" com uma peculiaridade bem interessante do tempo, pois:

Quando dele falamos, compreendemos o que dizemos. Compreendemos também o que nos dizem quando dele nos falam. [...] Se ninguém mo [sic.] perguntar, eu sei; se o quiser explicar a quem me fizer a pergunta, já não sei. Porém, atrevo-me a declarar, sem receio de contestação, que, se nada sobreviesse, não haveria tempo futuro, e se agora nada houvesse, não existiria o tempo presente (Conf., XI, 14, 17).

A partir das palavras de Agostinho acima citadas, percebe-se que o mesmo escreve estando ciente das dificuldades que decorrem ao desenvolver uma resposta para uma questão tão difícil como essa. No entanto, buscando superar tais dificuldades, Agostinho inicia sua investigação em torno da concepção de passado, presente e futuro.

No início da investigação já surge uma questão bem interessante, pois, "De que modo existem aqueles dois tempos - o passado e o futuro - , se o passado já não existe e o futuro ainda não veio?" (Conf., XI, 14, 17) Como conceber que o tempo passado existe, se o mesmo já passou, já deixou de ser? E o futuro, como afirmar sua 
existência, se o mesmo ainda não se tornou presente e, assim como o passado, não é?

Uma questão ainda mais peculiar surge em relação ao tempo presente, pois, “[...] se o presente, para ser tempo, tem necessariamente de passar para o pretérito, como podemos afirmar que ele existe, se a causa da sua existência é a mesma pela qual deixará de existir?" (Conf., XI, 14, 17) De que modo se dá sua existência, se o mesmo só existe enquanto tempo pelo fato de deixar de existir a todo instante, tornando-se assim pretérito? Sem dúvida, estas questões são de grande relevância e complexidade, porém, seguindo o "caminho" reflexivo feito por Agostinho, as mesmas serão analisadas mais tarde, pois, antes disso, o pensador se detém a examinar a "longevidade" e "brevidade" dos tempos futuros e passados, assim como a forma correta de mencioná-los.

Passado e futuro podem ser "longo" ou "breve”? Segundo Agostinho:

Chamamos "longo" ao tempo passado, se é anterior ao presente, por exemplo, cem anos. Do mesmo modo dizemos que o tempo futuro é "longo", se é posterior ao presente também cem anos. Chamamos "breve" ao passado, se dizemos, por exemplo, "há dez dias"; e ao futuro, se dizemos "daqui a dez dias". Mas como pode ser breve ou longo o que não existe? Com efeito, o passado já não existe e o futuro ainda não existe. Não digamos: "é longo"; mas digamos do passado: "foi longo"; e do futuro: "será longo" (Conf., XI, 15, 18).

Percebe-se a partir desta passagem que o pensador ressalta o modo correto de mencionar um tempo passado ou futuro. Como observado, não se deve dizer que um tempo passado ou futuro é "breve" ou "longo", mas sim, foi ou será "breve" ou "longo", pois, de certo modo, afirmar que algo que ainda não existe (futuro) ou que existiu e não existe mais (passado) é, sendo que tudo o que é, só é enquanto presente é contraditório. No entanto, de que maneira um tempo passado pode ser considerado breve ou longo? "O tempo longo, já passado, foi longo depois de passado ou quando ainda era presente?” (Conf., XI, 15, 18) Avançando em sua análise, Agostinho percebe que afirmar a longevidade de um período de tempo que já passou, é no mínimo questionável:

Não digamos pois: "o tempo passado foi longo", porque não encontraremos aquilo que tivesse podido ser longo, visto que já não existe desde o instante em que passou. Digamos antes: "aquele tempo presente foi longo", porque só enquanto foi presente é que foi longo. Ainda não tinha passado ao não-ser, e portanto existia uma coisa que podia ser longa. Mas, logo que passou, simultaneamente deixou de ser longo, porque deixou de existir (Conf., XI, 15, 18).

Mas de que modo um tempo presente pode ser longo? Refletindo em torno desta questão, Agostinho aborda como exemplo (no paragrafo 19) "um século". Sem 
dúvida, um século é um longo período de tempo. No entanto, como é possível existir um século de presente? A partir do exemplo dado por Agostinho, é possível compreender a impossibilidade de até mesmo o presente ser longo. Ora, um século não pode ser todo presente, pois, cada ano que passa se torna passado e, desta forma, já não pode ser afirmado como presente. O mesmo decorre com cada mês do ano e com cada dia do mês, assim como, com cada hora do dia e cada instante da hora. Ou seja, o presente se reduz de tal modo que sua divisão torna-se impossível. Porém, caso possível chegar até este instante indivisível de tempo, poder-se-ia afirmar que "[...] este voa tão rapidamente do futuro ao passado, que não tem nenhuma duração. Se a tivesse, dividir-se-ia em passado e futuro. Logo, o tempo presente não tem nenhum espaço" (Conf., XI, 15, 20).

Assim como ocorre com o passado, também ocorre com o futuro. Da mesma forma, ambos carecem de longevidade. Não é possível dizer que um não existente é longo, pois só tem possibilidade de ser longo aquilo que é. O futuro ainda não é. Logo, o futuro não pode ser considerado longo. A única possibilidade de um período de tempo ser considerado longo se dá no instante de existência (presente), mas, como observado acima, "[...] o tempo presente clama que não pode ser longo" (Conf., XI, 15, 20).

Percebe-se, assim, que o tempo presente é algo que "escapa” à percepção do ser humano. Os instantes presentes tornam-se pretérito tão rapidamente que não possuem nenhuma duração. Porém:

[...] percebemos os intervalos dos tempos, comparamo-los entre si e dizemos que uns são mais longos e outros são mais breves. Medimos também quando este tempo é mais comprido ou mais curto do que outro, e respondemos que um é duplo ou triplo, ou que a relação entre eles é simples, ou que este é tão grande como aquele (Conf., XI, 16, 21).

Mas de que modo isso ocorre? Como afirmado anteriormente, passado e futuro não possuem existência. Só o presente existe. Porém, sua existência é tão curta que nem se quer possui duração. Como é possível conceber a duração dos intervalos de tempo? Como é possível medi-los e compara-los? De certo modo, Agostinho responde a estas questões afirmando: "Existem, portanto, fatos futuros e pretéritos" (Conf., XI, 17, 22).

De certa forma, pode-se inferir a ideia de que Agostinho faz uma divisão dentro de sua teoria do tempo, como afirma José Renivaldo Rufino, “[...] trabalhada por dois lados: um viés que considera o tempo da consciência (tempo subjetivo), e outro que leva em conta a consciência do tempo (tempo objetivo)." (RUFINO, 2003, p.23) Considerando o modo com o qual Rufino nomeou os dois lados trabalhados por Agostinho, é possível afirmar que até o momento, a investigação do presente estudo se deu somente em torno do tempo objetivo. 
Em um primeiro momento de sua investigação relacionada ao tempo, é possível perceber que Agostinho "explora" apenas o tempo objetivo. Já ao afirmar que existem fatos futuros e pretéritos, o pensador sinaliza um "movimento dentro da teoria", dando os primeiros indícios de que pode haver outra forma de conceber o tempo. A partir de então, Agostinho inicia uma investigação em torno do tempo da mente $^{3}$ (tempo subjetivo ${ }^{4}$ ), surgindo assim, novos elementos na teoria. É o que será visto a seguir.

\section{Tempo mental}

Se for possível a existência de coisas futuras ou pretéritas, "[...] sei todavia que em qualquer parte onde estiverem, aí não são futuras nem pretéritas, mas presentes." (Conf., XI, 18, 23) Agostinho inicia sua investigação em torno do tempo da mente a partir da proposição acima citada. Assim como ocorre com o tempo objetivo, tudo o que existe no tempo da mente existe unicamente no presente. Mas, de que modo as coisas passadas se tornam presentes? Agostinho responde:

Ainda que se narrem os acontecimentos verídicos já passados, a memória relata, não os próprios acontecimentos que já decorreram, mas sim as palavras concebidas pelas imagens daqueles fatos, os quais, ao passarem pelos sentidos, gravaram no espírito uma espécie de vestígios. Por conseguinte, a minha infância, que já não existe presentemente, existe no passado que já não é. Porém a sua imagem, quando a evoco e se torna objeto de alguma descrição, vejo-a no tempo presente, porque ainda está na minha memória (Conf., XI, 18, 23).

Percebe-se, assim, que as ocorrências do passado, apesar de carecerem de existência extramental5, existem enquanto memória. Esse modo de existir só é possível devido ao fato de o ser humano perceber, através dos sentidos, o que ocorre em cada instante. Essa percepção do presente, de certo modo, acaba por deixar, como afirma Agostinho, na citação acima, "uma espécie de vestígios" no espírito. Em momento presente, quando evocados pelo espírito, esses vestígios são relatados pela memória através de palavras, possibilitando, assim, que as ocorrências passadas existam novamente, mas, desta vez, como imagem mental. Desta forma, aquilo que era em um determinado instante e, necessariamente, deixou de ser no instante posterior, não pode mais existir do modo que foi. Sua existência fica restrita à mente.

Já as ocorrências futuras, "a maior parte das vezes, premeditamos [...], e essa premeditação é presente, ao passo que a ação premeditada ainda não existe, porque

\footnotetext{
3 O que Rufino denominou por tempo subjetivo, Agostinho denomina como tempo da mente. $\mathrm{O}$ tempo da mente é o modo com o qual o espírito do sujeito concebe o tempo.

4 “Do, ou existente no sujeito. Individual, pessoal." (Dicionário Aurélio, 8ed, 2014)

${ }^{5}$ Aquilo que é externo a mente. Não depende da mente para possuir existência.
} 
é futura." (Conf., XI, 18, 23) Do mesmo modo como ocorre com "aquilo" que é pretérito, as ocorrências futuras não possuem existência extramental. O que existe é uma imagem concebida pelo espírito de uma possível ocorrência futura. Mas de que modo isso ocorre? A resposta para esta questão será investigada de modo aprofundado posteriormente. Primeiramente é importante destacar o que Agostinho conclui em relação a passado, presente e futuro.

Como já afirmado acima, tudo aquilo que existe, existe no presente. Deste modo, Agostinho conclui que:

É impróprio afirmar que os tempos são três: pretérito, presente e futuro. Mas talvez fosse próprio dizer que os tempos são três: presente das coisas passadas, presente das presentes, presente das futuras. Existem, pois, estes três tempos na minha mente que não vejo em outra parte: lembrança presente das coisas passadas, visão presente das coisas presentes e esperança presente das coisas futuras. Se me é lícito empregar tais expressões, vejo então três tempos e confesso que são três (Conf., XI, 20, 26).

A partir desta passagem, é possível perceber um elemento bem interessante da teoria de Agostinho, sendo este, a existência dos três tempos (presente, passado e futuro) unicamente na mente e em tempo presente. Desta forma, é possível afirmar a existência do tempo como um presente uno e triplo. Ou seja, sua unidade, reside no fato do mesmo existir apenas enquanto presente. Já sua tripartição, como observado na citação acima, é devido à possibilidade de existência em três momentos: "lembrança presente das coisas passadas, visão presente das coisas presentes e esperança presente das coisas futuras.” Esses três momentos só são possíveis porque a alma humana também é una e tripla. Sua unidade se dá enquanto uma só alma. Sua triplicidade ocorre devido ao fato de ser composta por três "faculdades": memória (lembranças), inteligência (visão) e vontade (esperança). Ciente disto, avançar-se-á à investigação tendo como foco a concepção agostiniana de futuro.

\section{Futuro enquanto expectação}

De que modo se prediz o futuro? "Confesso-Vos, meu Deus, que não sei se a causa pela qual se prediz o futuro equivale ao fenômeno de se apresentarem ao espírito as imagens já existentes das coisas que ainda não existem.” (Conf., XI, 18, 23) Apesar de não ter certeza da causa da predição, Agostinho afirma com certeza, como citado anteriormente, que ao predizer algo, prediz-se presentemente, no entanto, a ação que foi premeditada ainda não existe, pois esta é futura. Esta ação só existirá quando a mesma for realizada, deixando de ser futura e tornando-se presente. "Por esses vaticínios é apenas profetizado o futuro já preconcebido na alma. Esses vaticínios, repito, já existem, e aqueles que predizem o futuro já os vêem como presentes junto a si." (Conf., XI, 18, 24) Ou seja, o ato de predizer o futuro se 
dá em momento presente. A imagem da predição está presente no espírito de quem profetiza o momento futuro, mas a ocorrência extramental deste vaticínio ainda não possui existência. Nem as observações, nem a imagem concebida no espírito, se igualam à ocorrência extramental do vaticínio. Logo, as coisas futuras não possuem existência.

Para melhor ilustrar a ideia, Agostinho aborda um exemplo em sua investigação:

\begin{abstract}
Vejo a aurora e prognostico que o sol vai nascer. O que vejo é presente, o que anuncio é futuro. Não é o sol que é futuro, porque esse já existe, mas sim o seu nascimento, que ainda se não realizou. Contudo, não o poderia prognosticar sem conceber também, na minha imaginação, o mesmo nascimento, como agora o faço quando isso declaro. Mas nem aquela aurora que eu vejo no céu e que precede o aparecimento do sol, nem aquela imagem formada no meu espírito são o mesmo nascimento do sol, ainda que, para se predizer este futuro, se devam enxergar a aurora e a sua imagem como presentes (Conf., XI, 18, 24).
\end{abstract}

Percebe-se, assim, a possibilidade de predizer o futuro a partir de observações das coisas já existentes (presente). No exemplo de Agostinho, observa-se a aurora e, a partir da mesma, concebe-se uma imagem no espírito de quem observa, sendo esta correspondente a um instante futuro: o nascimento do sol. Porém, este instante ainda é futuro e, por consequência, carece de existência extramental. A única coisa que existe até então é uma imagem presente de uma possível ocorrência futura. Logo, o futuro existe apenas enquanto imagem mental. "Mas como diminui ou se consome o futuro, se ainda não existe? [...] Quem, por conseguinte, se atreve a negar que as coisas futuras ainda não existem?" (Conf., XI, 28, 37).

Avançando em sua investigação, Agostinho desenvolve uma resposta bem interessante para os questionamentos acima citados. Como visto até o presente momento, o futuro carece de existência extramental, existindo apenas enquanto imaginação presente. Longevidade ou brevidade são estranhas ao futuro. Porém, no decorrer do desenvolvimento da análise, o conceito de futuro se estende, de tal modo que, enquanto expectação, pode até ser considerado longo ou breve. Em outras palavras, "[...] o futuro longo é apenas a longa expectação do futuro" (Conf., $\mathrm{XI}, 28,37)$ Ou seja, futuro longo enquanto algo extramental é impossível. Como já observado, não é possível o futuro ser longo ou breve, pois o mesmo ainda não existe. Mas é possível que exista no espírito do ser humano uma longa ou breve expectação em relação ao futuro. De certo modo, algo semelhante ocorre com o passado. Assim como o futuro, o passado, enquanto algo extramental, não pode ter brevidade ou longevidade, pois carece de existência. No entanto, pode ser concebido pelo espírito como uma longa ou breve lembrança do passado. Para melhor ilustrar a ideia, Agostinho expõe um exemplo: 
Vou recitar um hino que aprendi de cor. Antes de principiar, a minha expectação estende-se a todo ele. Porém, logo que o começar, a minha memória dilata-se, colhendo tudo o que passa de expectação para o pretérito. A vida deste meu ato divide-se em memória, por causa do que já recitei, e em expectação, por causa do que hei de recitar. A minha atenção está presente e por ela passa o que era futuro para se tornar pretérito. Quanto mais o hino se aproxima do fim, tanto mais a memória se alonga e a expectação se abrevia, até que esta fica totalmente consumida, quando a ação, já toda acabada, passar inteiramente para o domínio da memória (Conf., XI, 28, 38).

Nesta passagem de Agostinho, é importante notar a utilização da palavra "estende-se". Enquanto tempo da mente, para Agostinho, "[...] o tempo não é outra coisa senão distensão [...]”. (Conf., XI, 26, 33) Esta distensão ocorre na alma. A distensão da alma (Distentio Animi) possibilita medir o tempo, comparar um período de tempo com outro, afirmar que é longo ou breve. É na alma que se mede os períodos de tempo. Ou seja, no tempo da mente, a alma se movimenta. Um movimento de ir e vir, alternando entre passado e futuro.

A alma concebe o futuro através de expectação. Quanto mais longa for a expectação, mais a alma se estende. A cada passar de instante, a expectação diminui. A expectação que era longa se consome aos poucos. Dividindo-se em instantes, vai "escoando" para um momento dotado de atenção (presente), tornando-se, no passar de cada instante, pretérito, "salvando-se" enquanto memória. Percebe-se, assim, que o futuro nada mais é do que uma expectativa concebida pelo espírito, e, como afirma Rufino, esta "[...] expectativa, ou esperança, tem como dinâmica o todo da vida ou a vida como um todo" (RUFINO, 2003, p.87).

Desta forma, percebe-se que, além do fato de só existir na mente, o futuro existe apenas enquanto expectação. Esta expectativa pode ocorrer de duas formas: através de uma imagem antecipada (vaticínio) ou pela simples ação de esperançar. No primeiro caso, a partir da observação de suas causas, em momento presente, devido à influência do âmbito externo, criam-se imagens no espírito do ser humano, referentes a coisas que ainda não são (futuro). No segundo caso, ocorre somente a expectação, devido ao fato dessa não se originar a partir de imagens antecipadas referentes a observações de causas. Em outras palavras, como afirma David Camilo, o futuro só existe "[...] como uma imagem antecipada, em minha consciência, daquilo que se impõe sobre mim como determinação externa ou como aquilo que espero e aguardo" (CAMILO, 2008).

\section{Considerações finais}

A análise de Agostinho em torno do tempo é, sem dúvida, muito completa e bem elaborada. Através do estudo foi possível perceber que passado e futuro possuem existência somente no espírito dos indivíduos, devido ao fato de ambos 
serem tomados como instâncias distintas do presente. Como observado, o passado é concebido pelo espírito enquanto lembranças dos momentos presentes que já não são, ou seja, que já passaram. Em momento presente, estas lembranças podem ser evocadas pelo espírito e existirem novamente enquanto imagem. Já o futuro, conforme observado, existe unicamente enquanto expectação, através de uma imagem antecipada (vaticínio) ou pelo "simples" ato de expectar.

Percebe-se, assim, que o futuro e o passado existem somente no espírito. Ou seja, o tempo enquanto algo externo ao indivíduo carece de passado e futuro. Sua existência se dá unicamente nos instantes de presente. Seu modo de existir é único. A tripartição do tempo identificada por Agostinho ("lembrança presente das coisas passadas, visão presente das coisas presentes e esperança presente das coisas futuras") é exclusividade do espírito.

Parece ser exatamente neste ponto que surge a subjetividade do tempo. $\mathrm{O}$ modo com o qual cada indivíduo concebe o tempo em seu espírito é único. As memórias de cada indivíduo são totalmente individuais. Assim como suas expectativas para o futuro. As esperanças que cada indivíduo "acolhe" em seu espírito são restritamente particulares, de tal modo que alguns instantes de tempo podem parecer longo para uns e breve para outros. Por exemplo: os dois minutos finais de expectação de uma partida de futebol decisiva podem parecer um longo tempo para um torcedor do time que está ganhando. Já para um torcedor do time que está atrás no placar, os mesmos dois minutos parecem ser brevíssimos. Assim sendo, pode-se afirmar que a brevidade ou longevidade de um período de tempo é dependente do "estado de espírito" de cada um.

\section{Referências}

AGOSTINHO. Confissões. Trad. de Oliveira Santos; Ambrósio de Pina. 2. ed. São Paulo: Abril Cultural, 1980.

AURÉLIO, O mini dicionário da língua portuguesa. 8a edição revista, atualizada e ampliada. Editora Positivo. Impressão - Rio de Janeiro, 2014.

CAMILO, D. A concepção de tempo em Santo Agostinho. [S.1.:S.n], 11 ago. 2008. Web Artigos. Disponível em: <http://webartigos.com/artigos/a-concepcao-de-tempo-emagostinho/8524>. Acesso em 10/06/2017.

DANILAS, S. O conceito de tempo em Agostinho: Diálogo com a ciência de hoje. Curitiba: Champagnat, 2009.

RUFINO, J. R. Passado, Presente e Futuro: O tempo da consciência e a consciência do tempo no pensamento de Santo Agostinho. 2003. 179f. Dissertação (Mestrado) - Universidade Federal de Pernambuco. CFCH. Filosofia, 2003.

Submissão: 17.07.2017 / Aceite: 10.11.201. 